DOI: $\underline{\text { https://doi.org/10.24867/04IH01Kovacevic }}$

\title{
IMPLEMENTACIJA STANDARDA ENERGETSKE EFIKASNOSTI ISO 50001 U PROIZVODNOM SISTEMU
}

\section{IMPLEMENTATION OF THE ENERGY EFFICIENCY STANDARD ISO 50001 IN THE PRODUCTION SYSTEM}

\author{
Miloš Kovačević, Fakultet tehničkih nauka, Novi Sad
}

\section{Oblast - MEHATRONIKA}

Kratak sadržaj - U ovom radu opisan je način uvođenja ISO 50001 standarda u kompaniju JC. Standard ne propisuje samo primenu modernih ili novih tehničkih rešenja, već $i$ potrebu za kvalitetnim upravljanjem energijom $i$ osposobljenost osoblja da na adekvatan energetski efikasan način upravlja kako opremom tako $i$ energijom. U ovom radu su predstavljene prakse i rešenja prepoznati u okviru kompanije $i$ njihova potpuna implementacija na tehničkom i organizacionom nivou.

Ključne reči: ISO 50001, menadžment energije, energetska efikasnost, prakse.

Abstract - This paper describes how to introduce the ISO 50001 standard in the company JS. The standard does not prescribe only the application of modern or new technical solutions, but also the need for quality energy management and the ability of personnel to manage in an energy efficient manner both equipment and energy. In this paper, presentation of practices and solutions recognized within the company and their full implementation at the technical and organizational level is given.

Key words: ISO 50001, energy management, energy efficiency, practice.

\section{UVOD}

Prema standardu ISO 50001, koji pruža zahteve za sisteme menadžmenta energije, "sistem menadžmenta energije" je definisan kao skup međusobno povezanih i međusobno delujućih elemenata, koji imaju za cilj da se uspostavi energetska politika i energetski opšti ciljevi, uključujući i procese i procedure za dostizanje tih opštih ciljeva [1]. Kroz okvir menadžmenta energijom u organizacijama, kako preporučuje međunarodni standard ISO 50001, ogranizacije treba uspostave programe ušteda energije kojima se ostvaruju energetska efikasnost i konkurentnije poslovanje.

Ovi programi treba da istaknu prioritetna ulaganja $u$ projekte energetske efikanosti, koje jedno preduzeće ima za cilj da realizuje[2]. Međunarodna organizacija za standardizaciju (ISO) je identifikovala energetski menadžment kao jednu od pet najznačajnijih oblasti koja zahteva razvoj i promociju međunarodnih standarda. Zasnovan na široj primeni kroz nacionalne ekonomske sektore, budući standard može da utiče na do $60 \%$ svetskih potreba za energijom.

\section{NAPOMENA:}

Ovaj rad proistekao je iz master rada čiji mentor je bio dr Milovan Lazarević, vanr. prof.

\section{PLAN IMPLEMENTACIJE}

Iako je prvenstveno namenjen industriji, standard je primenljiv na bilo koji tip organizacije koja želi da uspešno upravlja korišćenjem energije i energetskom efikasnošću [3].

Kao multinacionalna kompanija Johnson Controls je standardizovao korake prilagođene za sve svoje proizvodne jedinice i oni su [4]:

1) Izabrati koordinatora programa. Koordinator je odgovoran za vođenje tima za implementaciju standarda.

2) Sastaviti tim. Tim je potrebno obučiti za korišćenje alata za implementaciju, praksi i procesa. Tim za EM sastoji se od članova iz proizvodnog održavanja i inženjeringa, upravljanja proizvodnjom i radne snage generalne proizvodnje. Preporučuje se uključivanje upravljanja postrojenjima i centralnih funkcija kao što su ljudski resursi ili finansije.

3) Prikupiti i analizirati podatke. Sakupljaju se informacije o korišćenju energije u preduzecu. Pregledaju se postojeći projekti energetskog poboljšanja postrojenja, trendovi potrošnje energije i ciljevi smanjenja proizvodnje. Pored toga, pregledi prošlih računa za energetiku su neophodni kako bi se identifikovale mogućnosti za projekte za ustedu energije. Članovi tima je potrebno da planiraju akcije zajedno kako bi identifikovali mogućnosti ili vrste postupaka upravljanja energijom kojima je potrebno pružiti najveću pažnju.

4) Uspostaviti plan komunikacije u kompaniji kako bi se podstakli zaposleni da postanu aktivni učesnici u identifikovanju novih mogućnosti poboljšanja i preduzimanju akcija za smanjenje potrošnje energije.

5) Proceniti svaku primenu upravljanja energijom. Praksa upravljanja energijom koja je najrelevantnija za energetski menadžment se bira na osnovu procene kompanije. Kalkulator štednje energije koristi se za procenu potencijalne uštede različitih aktivnosti i mera. Prema završenom rasporedu, sva područja prakse upravljanja energijom trebaju biti pokrivena jednom u kvartalu.

6) Unositi projekte u CI-TRAC. Jednom kada se implementiraju prakse za energetski menadžment koji je kvalifikovan i njegov prioritet uspostavljen, one se unose $u$ CI TRAC.

7) Praviti mesečne preseke. Kao deo normalne mesečne operativne nadogradnje, tim se sastaje mesečno kako bi pratio napredak u merama za poboljšanje objekta zabeleženih u CI TRAC-u i energetskim aktivnostima održavanja. Tim daje pismene izveštaje o napretku sa mesečnim ažuriranjima projekta kako bi obavestio rukovodstvo o tome šta je postignuto tokom proteklog meseca $\mathrm{i}$ šta je planirano za naredni mesec. 
8) Ponoviti proces. Program za uštedu energije je ireverzivni i kontinuirani proces koji zahteva podršku putem česte komunikacije i prepoznavanja aktivnosti i dostignuća programa EM. Pored toga, potrebno je ohrabrujuće aktivno učešće celog osoblja postrojenja.

\section{UPRAVLJANJE TROŠKOVIMA ENERGIJE}

Pod upravljenjem troškovima energijom nalazi se proračun potrebne energije, rukovanje procesima i potrošnjom sa minimalnim gubicima, korišćenje opreme koja je efikasna [5]. Oprema koja se koristi u kompaniji je visokoefikasna, planirana prema standardu i zahtevima JC-a. Jedini način da se utiče je redovno održavanje što se i čini. Veoma važan činilac u upravljanju energijom, korekcija faktora snage, je postavljena u startu na visok nivo od 0,99. Pregledom računa potrošnje energije, ugovorene snage maksigrafa i očitanih vrednosti uočena su četiri meseca u kojima je maksigraf prekoračio dogovorenu isporuku. Prekoračenja ugovorene snage prouzrokuju visoke gubitke jer je u tom slučaju cena električne energije dva puta viša. Nakon pokretanja proizvodnje istovremenim uključivanjem mašina i opreme uz grejanje ili hlađenje prostorija trenutna potrošnja će preći ugovorenu tim više ukoliko su razlike spoljne i radne temperature veće. Iz ovoga se zaključilo da se pokretanje uređaja, mašina i sistema za grejanje i ventilaciju mora pokretati planski i sekvencijalno. Plan i procedura su pripremljeni i standardizovani. Smenovođe i tim održavanja su uključeni u pravilno i koordisano pokretanje proizvodnje, sistema grejanja, rasvete i sistema vazduha pod pritiskom. Na ovaj način izbegava se istovremeno priključenje svih uređaja na elektrodistributivnu mrežu i prekoračenje ugovorene snage.

\section{KOMPRIMOVANI VAZDUH}

Ušteda energije zbog poboljšanja sistema vazduha može da iznosi od 20 do $50 \%$ ili čak i više. Prva faza provere sistema je detekcija mesta curenja i provera filtara. Zaprljani filtari izazivaju padove vazduha pod pritiskom čime se rad kompresora povećava.

Provera je urađena pomoću dva nezavisna manometra, jedan manometar je povezan na vod vazduha pod pritiskom pre komponente kako bi se očitala vrednost pritiska pre ulaza u određeni element - merač ulaznog pritiska, dok je drugi manometar postavljen na vod vazduha pod pritiskom nakon komponente - merač izlaznog pritiska. Pad pritiska predstavlja razliku dva merena pritiska i značajniji pad je ustanovljen na sedam vodova[5]. Vodovi su obeleženi NOK labelom i uvršteni u plan održavanja.

Problem koji se u sistemima vazduha pod pritiskom povezuje sa značajnim uštedama koje se mogu postići je problem curenja. Procene mogućih ušteda kreću se od $30 \%$ do $60 \%$. Standard kompanije Johnson Controls preporučuje proveru curenja ultrazvučnom metodom. Predstavništvo kompanije SMC iz Beograda je uradilo proveru ultrazvučnim uređajem čime je izvršena lokalizacija curenja. Pronađeno je preko 30 curenja u sistemu na crevima, mestima spajanja i ventilima. Tim održavanja vodi evidenciju o mestima curenja, planu popravke i obeležavanju. Pored pomenute provere izvršena je i detekcija curenja starom metodom ispuštanjem mehurića koja je dala još približan broj mesta curenja jer ultrazvučna metoda nije pouzdana prilikom velikog šuma koji je prisutan u postrojenjima gde se vrši detekcija. Za ovu primenu potreban je deterdžent ili sapun pomešan sa vodom čime se oblažu sastavnice i razdelnici sistema vazduha pod pritiskom. Sistem provere curenja je uveden u plan održavanja kao redovna procedura.

Prepoznata je mogućnost zoniranja proizvodne hale, opreme i prostorija gde se koristi vazduh pod pritiskom (slika 1). Ugradnjom ventila sistem je podeljen tako da je u momentu uključena samo potrebna zona. Odgovorne osobe su zadužene za kontrolu uključenja-isključenja sistema prema potrebama. Smanjenjem radnog pritiska $u$ sistemu na optimalnu vrednost postiže se ušteda bez uticaja na performanse rada uređaja. Naime povećani radni pritisak povećava gubitke curenja, kompresor radi većim kapacitetom, a performanse sistema su iste. Kako većina uređaja radi na 6 bara, to se i uzelo kao optimalna mera pritiska u sistemu. Kompresor je podešen na radni pritisak u granicama od 5.8 do 6.7 bara. Uređaji koji rade na manje od šest bara su grupisani i ograničeni regulatorima na dodgovarajući nivo pritiska.

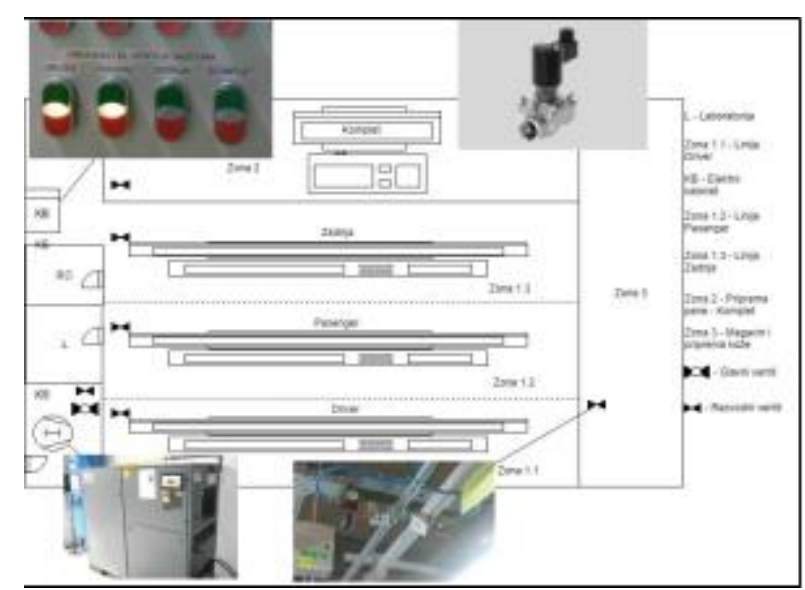

Slika 1. Izgled i mesto ugrađenih prekidača za zoniranje vodova

\section{RASVETA}

Rasveta čini znatan udeo u potrošnji električne energije. Dobra isplaniranost osvetljenja uz mogućnost upotrebe rasvete na onom mestu gde je potrebno u datom momentu predstavlja racionalno korišćenje električne energije. U kompaniji JC prema standardu za analizu potrošnje električne energije potrebno je uraditi sledeće:

- Izvršiti popis svih prostorija sa osvetljenjem, njihovu snagu i broj časova rada

- Izvršiti analizu opravdanosti rada sijalica u svakoj prostoriji prema potrebi i časovima upotrebe

- Izmeriti nivo osvetljenja na svakom radnom mestu i svakoj prostoriji.

Postavljanje senzora pokreta u prostorijama van proizvodne hale(toaleti, hodnici, svlačionice) predstavlja najpraktičnije i efikasnije rešenje. Nakon analize senzora i prema snazi koju mogu da podnesu(do 200W), ukupno osam senzora je postavljeno u prostorije toaleta, hodnika i svlačionica. Senzori su ugrađeni zonski. Ovim je izvršena ušteda u velikoj meri jer je do tada rasveta u navedenim prostorijama radila $24 \mathrm{~h}$ dnevno, pet dana u sedmici. Isključenje rasvete na onim mestima u kancelarijama $\mathrm{i}$ proizvodnji za vreme pauza. Dogovorena je procedura 
isključenja rasvete na radnim mestima koja nisu $u$ upotrebi $\mathrm{u}$ datom momentu. Za ovo je bilo potrebno omogućiti zonsko uključenje/isključenje dodatnim prekidačima (slika 2).

Prostor za uštede je prepoznat i kod mogućeg smanjenja nivoa osvetljenosti. Kako je nivo propisanog osvetljaja minimum 700 luksa(lx) izvršeno je merenje intenziteta osvetljenja u kompaniji.

$\mathrm{Na}$ mestima gde je nivo svetlosti bio iznad definisanog osvetljenje je redukovano na potrebni nivo redukovanjem broja lampi. Definisane su procedure uključenjaisključenja delova rasvete u skladu sa potrebama, a odgovorne osobe su imenovane za izvršenje.

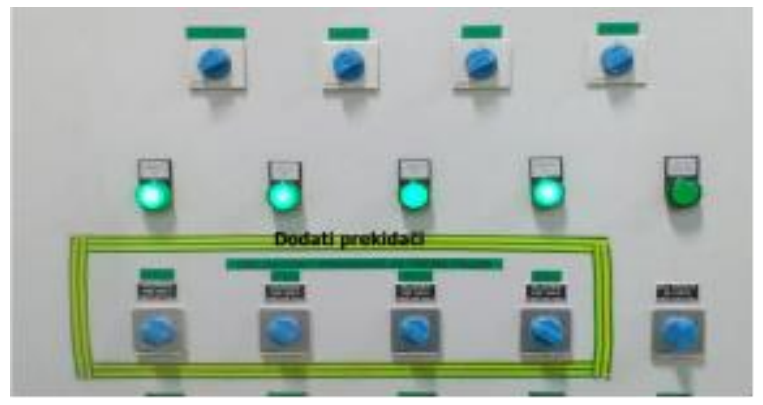

Slika 2. Dodati prekidači

\section{HVAC}

Sistemi grejanja, ventilacije i klimatizacije (HVAC) kontrolišu temperaturu, vlažnost i kvalitet vazduha kako bi osigurali ugodnu okolinu za ljude i pogodnu okolinu za rad opreme. U JC-u HVAC sistem je decentralizovan što daje mogućnosti za prilagođavanje potrebama svakog radnog mesta Ovo nam govori da kontrolu nad sistemom treba ograničiti na isključivo odgovorne osobe.

Dogovorena su tri koraka kao mogućnost ušteda: ograničenje radne temperature $\mathrm{i}$ isključenje tokom neradnih dana, redovan pregled i održavanje sistema i uključivanje svih zaposlenih u prakse čuvanja energije.

Mogućnost ograničavanja radne temperature. S obzirom da je propisana radna temperatura između 18 i 25 stepeni celzijusa regulatori grejanja su ograničeni na 21 stepen celzijusa što je optimalna radna temperatura tako da je izbegnuto subjektivno podešavanje radnih prostorija.

Osoba zadužena za kontrolu je menadžer zaštite na radu kao osoba odgovorna za kontrolu i implementaciju dogovorenog. Svaka promena radnih uslova se tako može uraditi samo uz njegovu saglasnost.

S obzirom da kompanija posluje u tri smene vođa projekta uštede HVAC sistema je dužan da obuči odgovornu osobu za svaku smenu o praćenju poštovanja dogovorenih praksi.

Čišćenje i pregled sistema grejanja kako bi se izbegli dodatni gubici je obuhvaćeno preventivnim održavanjem ali kako pukotine ili oštećenja u zidu i na fasadi zgrade mogu prouzrokovati povećane troškove energije, procedure preventivnog i prediktivnog održavanja zgrade su poboljšane. Takođe kako vrata ili prozori s pukotinom veličine $3 \mathrm{~mm}$ mogu propustiti vazduha koliko i rupa u zidu veličine cigle provera navedenog je ubačena u akcije održavanja. U okviru programa podizanja svesti i aktivnog uključivanja svih zaposlenih prezentovane su mere zaposlenima, a baneri su postavljeni na potrebnim mestima.

\section{SVEST I ANGAŽMAN ZAPOSLENIH}

Prakse koje mogu pomoći za efikasan program podizanja svesti zaposlenih i koje su implementirane i postavljene kao deo standardnih radnih aktivnosti su:

- Postavljajte pitanje o svesti na svakom mesečnom sastanku,

- Koristi medije kao što su monitori za podršku programima,

- Koristi postere i banere,

- Pratiti napredak i deliti rezultate,

- Prepoznati i nagraditi dobro ponašanje.

\section{MERENJE I PRAĆENJE}

Sva merenja potrošnje su merena kroz merače električne energije i gasa na taj način što su grupisane određene zone i na njima se direktno vršilo potrebno merenje potrošnje i uštede. Svi rezultati su praćeni kroz CI TRACK procedure koje su neophodne $\mathrm{u}$ procesu implementacije standarda za uštedu energije [6]. Sve izmerene i proračunate vrednosti potrošnje električne energije po tipu uređaja i zonama je potrebno uneti u tabelu(dodatak 1) za evidenciju potrošača kako bi se izračunali ukupni troškovi potrošnje energije. Pomenuta tabela je i parametar za merenje, praćenje i evaluaciju preduzetih koraka u menadžmentu uštede energije. Tabela se pravi iznova svake godine nakon čega imamo jasnu sliku potrošnje energije.

Merenje i praćenje se obavlja pre implementacije praksi gde je to moguće i nakon implementacije, rezultati se zatim upoređuju i oni će služiti za analizu, kako bi se ocenile efikasnosti ugrađenih praksi.

\section{REZULTATI I ANALIZA}

Nakon primene akcija i merenja pristupa se reviziji rezultata i korekciji praksi ukoliko je to potrebno. Na ovaj način se proverava efikasnost primenjenih mera $i$ doslednost u izvršavanju dogovorenog. Na slici 3 je grafik procesa implementacije komprimovanog vazduha odakle se vidi da je proces analize i korekcije dvosmeran.

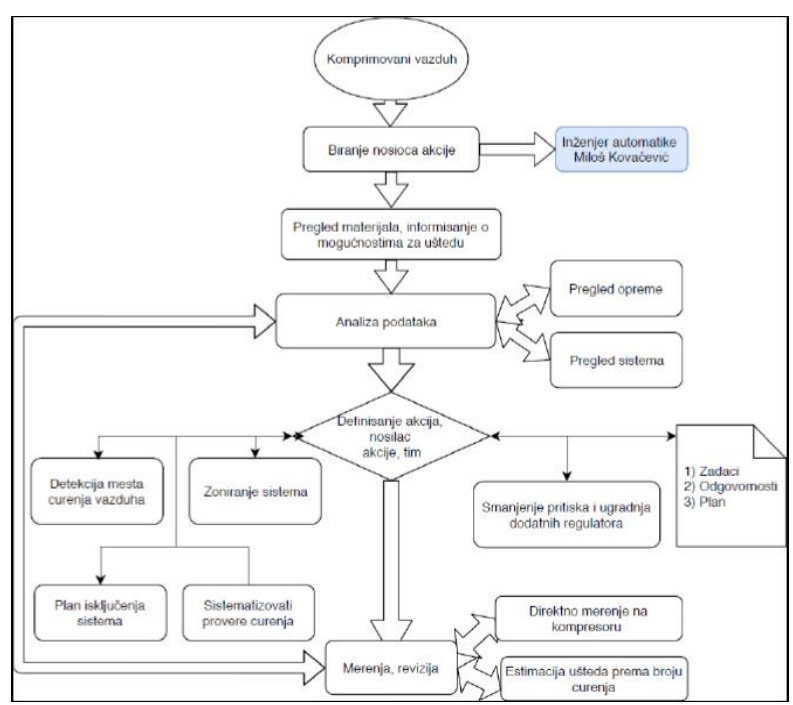

Slika 3. Grafik implementacije praksi ušteda u sistemu komprimovanog vazduha 
Na priloženom grafiku (slika 4) prikazano je koliko je smanjenje potrošnje električne energije u toku 2016 i 2017 godine nakon primene EnMS u odnosu na 2015 godinu pre primene mera štednje. Takođe preduzete mere i definisane procedure za plansko pokretanje opreme tokom 2016 i 2017 godine su rezultovale održavanje maksimalne snage u definisanim granicama, prekoračenja ugovorene snage nije bilo. Energetski pokazatelji zavisni od broja radnih dana i obima proizvodnje su najrealniji pokazatelj efikasnosti primenjenih akcija.

EP su izračunati na osnovu potrošnje energije po danu proizvodnje i po jedinici proizvoda. Oni pokazuju tendenciju smanjenja energije tokom 2016 i 2017 godine što govori u prilog uspešnosti praktične implementacije ISO 50001 standarda.

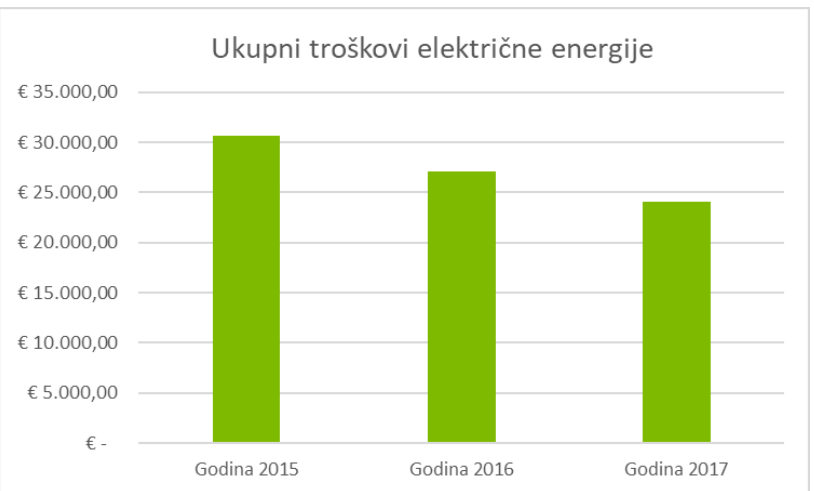

Slika 5. Rezultati pre i nakon primene EnMS

\section{ZAKLJUČAK}

Nema potrebe govoriti o važnosti energije, jer je poznato da je energija najveći ulaz u sve sisteme, ne samo industrijske proizvodne sisteme. Industrija je najvažniji sektor, koji utiče na čitavu ekonomiju. Potencijal za poboljšanje energetske efikasnosti kroz usvajanje praksi menadžmenta energije zavisi od veličine firme, vrste proizvodnje, energetskog intenziteta, stepena automatizacije proizvodnje, itd.

Standard ISO 50001 specificira zahteve za implementaciju sistema menadžmenta energije. Namena standarda je da omogući organizacijama da uspostave procese neophodne za poboljšanje energetske performanse. Energetska performansa obuhvata energetsku efikasnost, korišćenje energije ili neki drugi indikator. Primena standarda vodi ka smanjenju uticaja na životnu sredinu, ali i troškova za energiju. Može se primeniti u svim vrstama organizacija i u organizacijama svih veličina. Dakle, standard je po prirodi generički, kao i ostali standardi za sisteme menadžmenta, sa kojima ga je moguće integrisati. Može se reći da predstavlja razradu jednog specifičnog i važnog aspekta životne sredine, a to je svakako energija.

Cilj analize potrošnje energije $u$ predstavljenoj studiji slučaja je utvrđivanje indikativnih pokazatelja koji predstavljaju polaznu osnovu za preuzimanje odgovarajućih mera na smanjenju troškova električne energije kao i dobra podloga za kreiranje strategije energetskog razvoja. Strategija u energetskom razvoju JC ogleda se u prepoznavanju sopstvenih propusta i praksi koje su najprimenjivije u okviru kompanije.
Kao prioritetan operativni zadatak nameće se smanjenje troškova električne energije kroz eliminaciju gubitaka kako pomoću tehničkih rešenja ali i organizacionih koje mogu čak i premašiti uštede tehničkim sredstvima. Na kraju cilj je da svaki zaposlen ima svest o važnosti ušteda u energiji i da aktivno doprinosi programu.

Prema istraživanjima sistemski pristup upravljanja energetskom efikasnošću u većini kompanija nije primenjen, i u većini preduzeća postoje samo njegovi obrisi. Energetska politika se uglavnom ne definiše, korišćenje energije se planira sporadično, regulativa je ali standardi ređe. U kompaniji JC proces uspostavljanja praksi za upravljanje energijom je trajao godinu dana uz aktivno angažovanje menadžmenta i nosioca akcija. To nam kazuje da je implementaciju ovog standarda potrebno shvatiti ozbiljno i da samim postavljanjem sistema i promenama se završena samo jedna faza.

Sistem je potrebno unapređivati i održavati, za sve propisane i dogovorene akcije je potrebno imati odgovarajuću dokumentaciju i pisane procedure koje su deo obaveznih radnih rutina zaposlenih jer samo obučeni zaposleni sa tačno propisanim instrukcijama mogu biti garant da će se izvršavati propisane akcije.

Treba napomenuti da proces implementacije nije trajan, to znači da energetski lov treba da bude ugrađen u normalne operativne rutine i kulturu. To je tekući, iterativni proces i uvek postoji prostor za uštedu.

Konačan cilj jeste uključiti svakog zaposlenog da stekne svest o važnosti uštede energije i poštovanju procedura kako bi cela zajednica imala višestruku korist.

\section{LITERATURA}

[1] Jovanović, B. (2016). Sistem menadžmenta energije u prerađivačkoj industriji u Srbiji (doktorska disertacija). Beograd: Fakultet organizacionih nauka, str. 13.

[2] Gordić, D. et al. (2010). Development of energy management system - Case study of Serbian car manufacturer. Energy Conversion and Management, 51(12), 2783-2790.

[3] (2012). Standard SRPS ISO 50001:2012. "Službeni Glasnik RS", br. 80/12.

[4] Johnson Controls document “AE-LOS-FR-151 Evaluation_of_Energy_Aspects“"

[5] Milenković I. (2014). Kvalitet vazduha pod pritiskom u funkciji održive proizvodnje(doktorska disertacija)

[6] Johnson Controls document "Energy Hunt - Master Calculator (002) “

\section{Kratka biografija:}

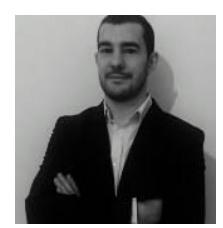

Miloš Kovačević rođen je u Loznici 1990. godine. Diplomski-master rad odbranio je 2018. godine na Fakultetu tehničkih nauka iz oblasti mehatronika - robotika. 